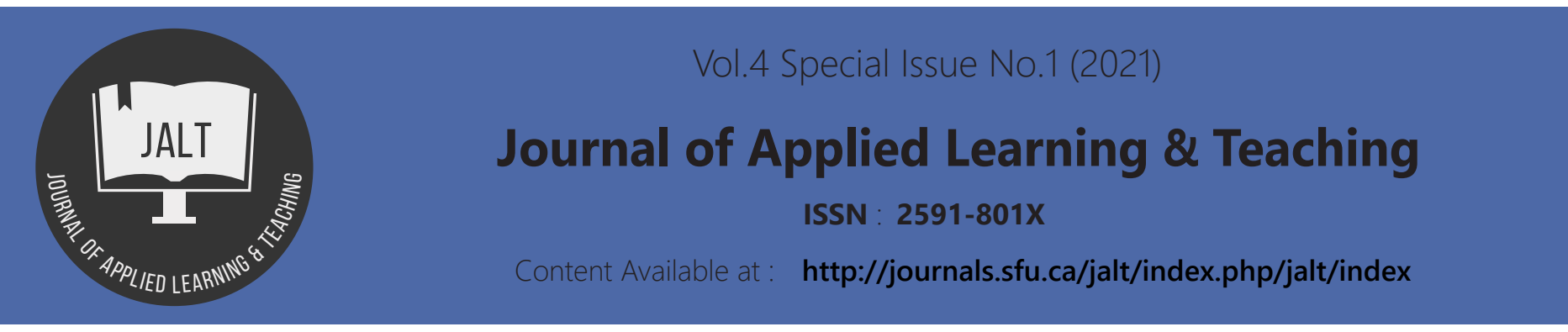

\title{
Presentation and Discussion
}

\section{Bras Basah Open: School of Theory \& Philosophy}

Stevphen Shukaitis: For this conference rather than a keynote from a single academic we decided to have one from an alternative educational project. Sticking with the divergence from traditional academic norms, rather than give a formal introduction of them I'd like to tell a little story.

I've been coming to Singapore fairly regularly since 2011. I don't want to rehash a whole list of cultural stereotypes about Singapore but it's not the kind of place you think you'd go to for finding experimental art, music and literature. But what I discovered is that after spending more time in Singapore is that in fact there's a lot of interesting things happening in those areas. And that ranges from things happening in terms of art at spaces like the Substation, or music being released by Ujikaji Records. And one of the most interesting projects I've been lucky enough to meet people from is the Bras Basah Open.

I remember going to one of their events. It was a Tuesday night. There were like 80 or 90 people coming out on a Tuesday night to talk about critical theory. That impressed me because people who were there had already done their readings and were really engaged with the topic. It struck me that here's another example of a group of people who are engaged in very interesting art, media, political work or activity outside of a formal institutional environment. When we came to organizing this conference it seemed really logical to invite them along to talk about their project and experiences.

Nazry Bahrawi: Thank you, Stevphen. I will start the presentation and there'll be two other speakers. So let me just go through it. We would first like to express thanks to Essex and also Kaplan, for inviting us to speak at what I think is a very timely conference, especially given the current conditions with Covid-19. Today Bras Basah Open School of Theory and Philosophy, or BBO for short, will be represented by three of five members. By way of a brief introduction, we are a collective of like-minded individuals from different disciplines and interests who want to help create an informal space for the public to discuss critical ideas and its application to society at large.
These are basically the contents for our presentation today. I've included here a brief that describes what we actually do. And this brief was taken from the Singapore Writers Festival booklet that we participated in last year, not the booklet but the event itself because it succinctly captures what we do.

You will also see the five core members here and I want to introduce them to you briefly in turn. On the far right of your screen is Shayus Shahida Sharif, who is an academic coach and learning facilitator. She'll be speaking later about pedagogy and the interfaces we use as a collective. To her right is Farhan Idris, researcher and educator trained in comparative philosophy. And to his right is Shawn Chua, researcher, dramaturge and artist in the field of the performing arts. Shawn will be speaking later on various entry points and anchors across the context we reference as well as one specific program that we run that we call TheoryFILM. Next to Sean is Nurul Huda, who is a researcher, writer and visual artist, who is infatuated with the idea or the venture of archiving knowledges and events. My name is Nazry Bahrawi and I'm an academic translator and literary critic, interested in decolonial thoughts and text across the Indian Ocean.

Sadly, Farhan and Nurul couldn't join us today because of other commitments. So the three of us will try to carry the presentation for them. As an informal collective, our ethos is not to represent ourselves as an organization. Instead, we each bring to BBO varying ideas and influences. In our discussion just prior to this presentation, Shawn puts it best when he described $\mathrm{BBO}$ as being refracted through each of our personal investments. And to give you a sense of how wide-ranging and diverse we are, we have created a mind map of the kinds of topics we tackle.

In terms of the coverage of the issues that we do, you will definitely notice some breadth, but I want to reassure you too that we do our best to try to delve deep into the topics we tackle. So, in the spirit of personal reflection, I would also like to introduce BBO in terms of how it came into being as a response to certain prevailing ideas in Singapore, when we first started back in 2018. We've just been about two years in operation. I say this by tapping into my experience as a 
humanities lecturer at an engineering university.

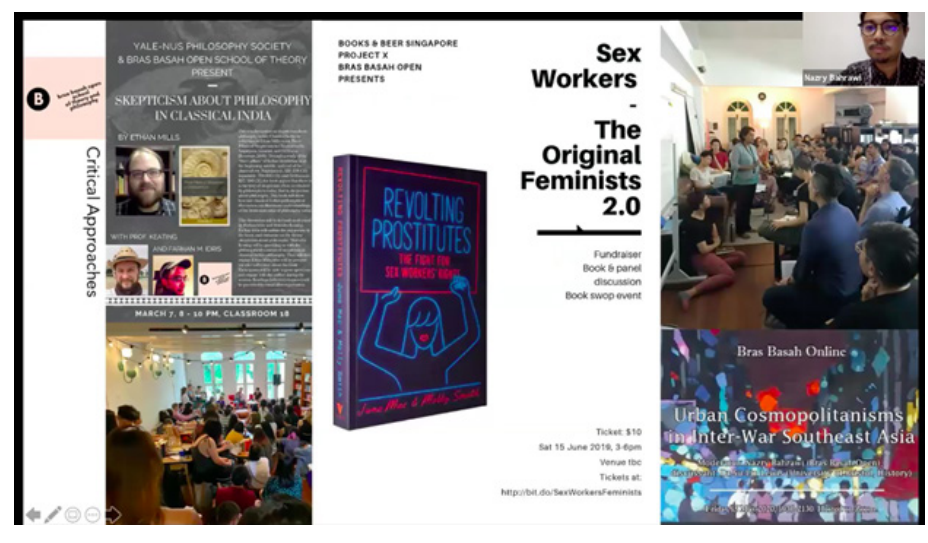

Figure 1: selected events organised by BBO.

On the screen, you will see some of the events that we've organised. Specifically, you will see three posters and two events. Stevphen earlier talked about the number of people that have attended our events and it's very encouraging, at least from the two pictures here. As the pictures indicate, most of the time we get quite a packed room of people, which is very encouraging to us in terms of what it represents. On the next slide you will see some of the ideas that we're responding to and I'm going to talk about them very briefly.

The first is the widespread idea of academia as an ivory tower. This basically means that knowledge produced by academics is only accessible to other academics, which creates a kind of elitism. This closed sphere of the academia is enabled by features such as the tenure track system, as well as restricted access to research materials and academic jargons. Another idea that I think we're responding to is the fear of abstraction, and by this I'm referring to the idea that theory has little contribution to the real world. This is an issue that resonates in many parts of the world - it's certainly not something that is unique to Singapore. But the fear of abstraction is even more pronounced in uber-pragmatic Singapore where ventures are often judged by what gains one can derive from them. Simply put, theory is held as airy fairy. And the third idea that I think we're spent responding to is the keen pursuit of democratization of knowledge.

This is also interrelated to the first two points. The warm response from the kinds and number of people joining us on Tuesday night just to have a heavy discussion, which sometimes lasts till beyond $10 \mathrm{pm}$, suggests that there is indeed a keen interest from folks in Singapore to participate in a process of knowledge creation that isn't dictated purely by the academia and that doesn't shy away from theoretical engagement.

In the next slide, I'll talk about how we kind of responded to all three of these. In response to this, I would like to outline the three frameworks that have been bandied about amongst ourselves, in our own discussions. These are informal academia, critical humanities and decoloniality.
Informal academia challenges the highly-bureaucratized university which in Singapore (and I think so too elsewhere) has turned the university into an institution that produces graduates to serve the economy. As a collective that is not limited by ideas of tenure or closed access to materials, we can operate slightly more freely. Critical Humanities meanwhile is a concept that can also be taken synonymously with public humanities. This basically means that we want to make available knowledges, theoretical concepts and frameworks to a wider audience outside of the university circle. This means building communities and seeing ourselves not as teachers, but as facilitators and enablers. We oftentimes in our events invite our audience members to suggest events and work with us and some of these have come to fruition. Especially so in Singapore, we have not quite taken to the humanities in the same way that the UK has taken to the humanities. In Singapore, we have established the Social Science Research Council, but we have not quite established an Arts and Humanities Research Council, nor do we have something equivalent to the Royal Society of Literature as an independent arts institution that supports and can give funding to promoting humanities research. We're missing the infrastructure for the flourishing of humanities in the public sphere. Bras Basah Open is one instance of how maybe some of us are responding to that. I use the term Critical Humanities, and the term 'critical' here means that while we engage theory, we also want to make the extra effort to try to contextualise the frameworks and concept to try to make sense of it in Singapore. I've already mentioned that a related idea here might be the notion of applied humanities. Our appeal to contextualisation and application is not so much a utilitarian idea. Rather we consider it a kind of decolonial move, and that is to say, we want to pursue the co-creation of knowledge by considering knowledges that make better sense to our lived experience and not to blindly import knowledges from elsewhere.

We've signalled this objective quite early on through our first book discussion with Professor Farid Alatas by reading chapters from his co-edited volume, Sociological Theory Beyond The Canon.

Shawn Chua: Thank you so much, Nazry, for kind of developing a framework for this and covering the ethos of Bras Basah Open. My background was in Cultural Anthropology and I did my Masters in Performance Studies and I've been working within the Performing Arts and as a researcher, educator and an artist. That's kind of the entry points that I have into this. During my section, I'll try to paint a little bit about the ecology in which our activities take place and I also take you through, more specifically, the TheoryFILM series.

This gorgeous map that was done by Nurul as a way to begin to draft the kind of themes that we keep coming back to. I think Nazry mentioned earlier, decoloniality is something that is a very important orientation for us and we do make a concerted effort to make sure whether it's in the programming of the films or speakers or the kind of readings as well that we are also casting the spotlight on academia and scholarship that is usually left out of the canon. And more importantly, to put them in conversation with the discourses that are happening. 


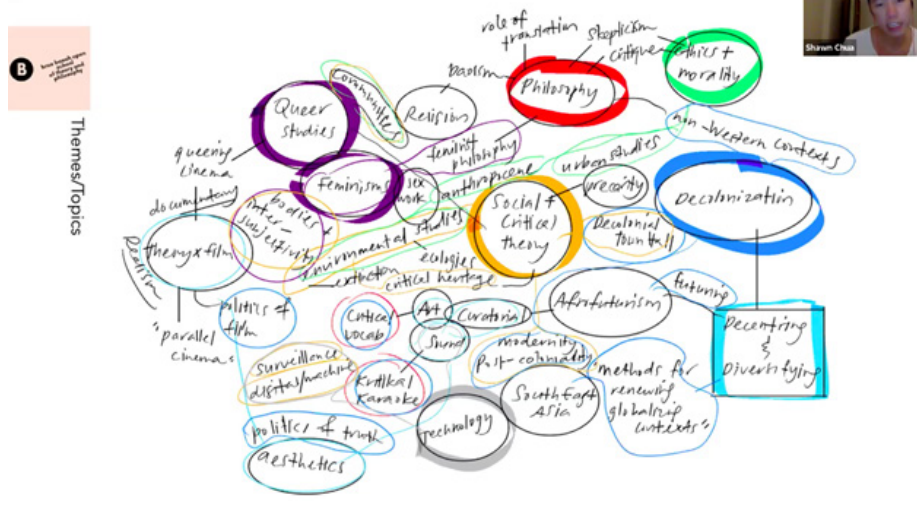

Figure 2: BBO's themes.

For the TheoryFILM series, this started in 2018. Our very first TheoryFILM was actually helmed by Nazry as well, and the idea behind TheoryFILM was that we wanted to play with the idea of pairings. This Theory Film as a series was actually a kind of collaboration between Bras Basah Open and soft/ WALL/studs, which is an independent art space in Singapore.

We were interested in thinking about what pairings can do. What happens when we pair theory and film. When we did this it was very clear that it wasn't about film theory necessarily, it wasn't exclusively about film theory. It's not about trying to apply the films to the theory, but we also want you to see how the film becomes a kind of theoretical intervention as much as the theory becomes a kind of filmic intervention.

How do these two different kinds of modalities begin to interact and juxtapose with each other? Usually the format of this series, how it works, is that we will assign a specific scholar. For the first one it was Svetiana Boym on nostalgia, paired with Elia Suleiman's film. Participants would get a reading, that is assigned by Svetlana Boym, they would come there watch the film together and then we begin to have a conversation.

Usually we should start with talking about the text a little bit before watching the film, and then we'll begin to see why the kind of resonances are happening and how each medium begins to offer a different kind of rereading of each of them.

The second session was Sara Ahmed. I believe it was Orientations... paired with the Funeral Parade of Roses. Then we had Nurul leading Nadine Labaki's Where Do We Go Now paired with Judith Butler. I did a session pairing Tiger of $\mathrm{Ma}$ laya with Tanabe Hajime.

It was about metanoetics [a way of doing philosophy that understands the limits of reason and the power of radical evil]. And I just wanted to stay with the Tiger of Malaya episode a little bit more, to give a bit of context as well. And I was the dramaturge for Singapore's Teater Ekamatra production of Tiger of Malaya. Tiger of Malaya was a World War Il Japanese propaganda film. We did a theatrical production that begins to unpack what it means to offer reparative accounts of history and begin to negotiate with these points of our history.
At Bras Basah Open, we decided to screen the original film as well and I think this is important because it's about situating how I actually see these kinds of TheoryFILM sessions and not necessarily as things operating out of silos or in isolation. We wanted to see how they can begin to extend the kind of discursive dimension to the kind of art world events that were happening, whether they were performances or exhibitions, and we'll see a bit more of that in some of our other programs as we go on.

Another wonderful one was with Lizzie Borden's film, it is a mockumentary. This particular iteration of TheoryFILM series was at that time at soft/WALL/studs. Divaagar, who is an artist, did this series called The Soul Lounge where he turned the space into a bar, it was a queer and brown solidarity bar. During the course of the installation, there were five interventions, one of those interventions was a TheoryFILM session which was Lizzie Borden's film.

I wanted to bring that out so that you begin to get a sense of how these TheoryFILM sessions - I think we did about 15 - are actually quite different in nature, how they're participating or being related to different kinds of events. That's part of the beauty of these pairings as well because I think what we wanted to play with is the kind of synergy of these pairings, to see what becomes undone and what new possibilities and conversations emerge when we take these conversations in a promiscuous way that is then engaged with all these different kinds of spaces and events. soft/WALL/ studs is housed in an industrial building in Geylang. Hence this aesthetic.

In our latest TheoryFILM session, this happened just a few months ago in April 2020 and it was on sickness and social choreographies. With this session, we're pairing Kelina Gotman's Choreomania: dance and disorder with a film. This particular iteration was special for a number of reasons. Firstly because, for those of you who are in Singapore, you would be familiar with the time, we were in the middle of the circuit breaker [lockdown], and actually in the months just trying to plan this event, it was so nerve-wracking. Every other day, there were new developments that were happening. There were so many questions about what is the context in which we're going to be organising this event and actually to organise an event at all just feels completely speculative and radical at that time, what is the future, what is one week later.

In the end this session became an online Zoom event and we kind of constrained it to about 20 participants. That was very interesting for a number of reasons because not only did all of us have to manage that transition of going on to these online spaces and adapting our programme to that, but I think one thing that changed for the films. Initially we had considered another film. It was by a Burmese filmmaker and I think it is called The Patient. We realized that firstly, the experience of watching a film on your laptops is a very different experience than watching it in a space. Secondly, we also realised that given the tenor of how we were all in very bleak, anxious times, we didn't necessarily want to screen the film that was to further cement those effects. 
Instead we decided to see what was native to these digital spaces. We became very curious about the viral videos that were going around, of dances around the virus. The one that you see here is, I believe, a police force in India that was doing a dance. I thought that was so fabulous on so many levels: On the realm of disciplining, but also in the kind of co-opting, and thinking about choreography across these different kinds of modalities. That was an interesting moment to then think about how then theory films in an age where we're all kind of live-streaming each other, we are all basically operating within a TheoryFILM. That was the kind of orientation that was happening there.

We were thinking a lot about how, rather than trying to adapt the theory from sessions into an online space it was more generative to then think about starting the online space, think about its affordances, what it can do and what it cannot do, as a kind of radically different possibility altogether and using that as a starting point and we framed this session as a kind of support group actually. At the start of the session we did a gesture exercise where we wanted people to think about involuntary gestures, involuntary movements that they see themselves doing. Whether out of anxiety or otherwise, during the pandemic period. Towards the end, which is the closing of the session itself, we started to get people to think about gestures of care with an object. This was a kind of way for us to begin to reach out to each other beyond this isolation that we were all experiencing and to kind of begin forging a different type of imagination of what a community can begin to look like.

Shayu Sharif: Stevphen had an event with us one time, whereby we discussed Combination Acts, the aesthetics of collective practice. This was sometime in April last year [2019], how time passes by. Stevphen put out a book [Gilman-Opalsky \& Shukaitis, 2019] and we actually had an event centred around that. If it's not obvious to everyone, the general flow of our sessions, if we are basing it on like a book, a title or a couple of chapters of a book, we would usually then pre-empt anyone who signs up for our sessions with a list of questions and certain issues that they can start thinking about as well as kind of like the prescribed chapters that they can read. I would say that that's the most prescriptive part about our events but for the most part, we are not really too hyper-vigilant about whether or not they do the readings, because we don't really want to recreate these uniform and kind of hierarchical formalized learning structures in our events.

Just to give you an idea about the event with Stevphen that we had, Farhan would usually start by situating a body of work against the backdrop of ideas in the case of Stevphen's book. Farhan would then sort of raise the issues, for example, why the social organization of artistic production should not be considered to be extraneous to the forms in art and cultural production. Who are the interlocutors in the field of art theory, sociology of art or organizational theory that the book is responding to, as well as the whole concept of the undercommons that was kind of a common thread that weaves throughout the book which is integral for us to understand artistic and cultural production. If the book is quite heavy going and if it demands a little bit of scaffolding on our end, we will usually do so before we get into the meat and potatoes of really discussing the book chapter or the book itself.

What usually proceeds is either a dialogue with the team member of Bras Basah with the author. If it's going to be an online kind of correspondence, we usually get the author to come online, usually via Skype, and then we will engage the author with some questions to just scaffold our general understanding of the key concepts and the main arguments of the book. Followed by that we usually have a break and then we would invite our participants to just go for it, like ask and engage the author in any questions that they might have pertaining to the book or pertaining to the issues that we did talk about. In that sense there is no predetermined scope of things that we need to discuss. The conversations will usually go in a way that the participants will want them to go to.

Another topic that we did talk about that I think was really interesting would be a work by James Chamberlain [2018], whereby we talked about the social function of work. His book was a critique of that. We also talked about universal basic income and other things like labour and citizenship and things like that. It was quite an interesting segue to talk about minimum wage issues in Singapore, as well as the other parts of the world. We do have sessions, whereby we collaborate with other like-minded organizations and informal groups.

We've had a session with the reading group which is quite a prominent group here in Singapore who mainly focus on Islamic issues and that session we had with them was to discuss a title by Souleymane Bachir Diagne called Open to reason: Pluralism in Islamic philosophical traditions. We invited some members from the reading group to scaffold the big issues about philosophical traditions within the Islamic tradition. And then we talked about geographies of reason and how Islamic philosophy should be extended to include philosophy in sub-Saharan Africa, of which the author of the book that we were reading argues for.

If you come to our sessions frequently enough, you do see a trend in how we run our sessions, usually the topics that we like to go for address things like philosophy from the margins, decoloniality and anything that really pushes our understanding of society, of justice and things like that. We do have quite a number of really hotly attended sessions and those usually tend to be the ones that do include some kind of a fundraiser. We've had two fundraisers so far. We had a session, whereby we raised funds for the T project and we paired it with a title.

The sex workers was one of it but we had another one. We were reading Jessica Hinchy's article "Transgender and queer lives in the colonial archive" and it was quite a fitting match because the $T$ project as an advocacy group does push quite heavily for trans-rights in Singapore. We do marry other titles with other fundraisers. As you can see here, we read Revolting prostitutes: The fight for sex workers' rights and we collaborated with Project X, not to be confused with the $T$ project. These events are really well supported by not only regulars to $\mathrm{BBO}$, but other people who are interested in advocacy as such. But it's not all really serious advocacy and 
activism, we do have things that are really quite out there and quite interesting as well. I think having something like this would be totally out of the question in this time and place, but late last year we had this very interesting event called Critical Karaoke. We can make anything critical in Bras Basah Open. The concept of Critical Karaoke was that we conceptualised karaoke to be a way in which we can confront neoliberal aesthetics and the concept of resilience. This event was the brainchild of our founder Farhan and basically the setup, if you're not familiar with Asia Bagus, it's quite campy but it's basically inviting contestants to showcase their vocal abilities and whatnot.

The twist here was that participants who did want to sing in front of an audience and be judged on that would have to give some short presentation about how the songs they have selected goes against the neoliberal aesthetic. I remember being on the panel with Shawn, we privileged songs that were not sung in a mainstream kind of language like English and so the minority languages were actually given some form of recognition in that sense. It was not all fun and laughter though, even though it was largely a very funny kind of event. Preceding the talk, Farhan gave a talk about karaoke, neoliberal aesthetics, and resilience and our good friend Bani Haykal, who is an artist here in Singapore, also gave a short talk sometime towards the end of the event about karaoke reverberations and coincidentally that event was also a fundraising activity for The Observatory. It's quite difficult for us to give you an idea of how we are like, but the sort of events that we do have is quite multifaceted, the range of topics and books that we do read together is really quite wide-ranging and we don't really impose some kind of membership criteria to be part of Bras Basah Open because we've had participants who had been attending quite a number of our sessions to actually give some kind of presentation on their own as well. So in that sense it's really a collaborative learning experience for all of us. And who knows, this whole visual mind map of the things that we dabble in might very well expand in the next years.

Shawn Chua: I wanted to bring up one point as well, because this is a symposium about alternative education and it's interesting because in terms of what our relationship with school is because we dropped 'school' at some point because it was an important signal or gesture. Just to reorient a different possibility of pedagogy that might not be, at least within the context of Singapore, the framework of the school as a very disciplinarian kind of apparatus and a hierarchical one.

What's also very interesting is the people who come to our events, especially reading groups. That's the moment where we realised there was a deep hunger for people who are not in academic spaces to have access to these spaces, or people who might have pursued academia to some degree at some point in their lives who then decided to go to other spaces, who wish to be nourished by the conversation again, we find them in these conversations or so. And depending on the topic, the kind of communication of the demographic in each of this event is actually very different.

We had this conversation with Farhan when we had one of our first events, was a Deleuze reading group, for example, and we were very clear that we kind of didn't want the space to be dominated by like Deleuze philosophy bros, for example, who are just flexing, like it's not about that. This is not about patronising or making education more accessible or easier, but rather it's about trying to harness the perspectives of people who might be coming from outside of philosophy, a kind of conventional philosophy training who might then be able to bring a very different kind of understanding or application. How do you begin to make sense? I think that's the part that is the richest for us and we want to facilitate that conversation in which we begin to make sense of ideas in a more diverse way as well.

\section{Discussion}

Stevphen Shukaitis: Thanks for that. That was wonderful. One thing I wanted to ask about is it seems that across your events you've stayed mainly within the humanities, which I can understand. But in terms of thinking about decolonising knowledge that perhaps it is through technical and apparently 'neutral' subjects, from business to architecture, that many forms of control continue to operate through. I wanted to ask if you're thinking through if opening and decolonising knowledge could operate through those areas as well.

Shawn Chua: I'll just give a quick response first and then I'll pass the time to the others. We also go beyond the humanities in the sense that we work quite a bit with science and technology studies as well, especially recently. For example, Nurul did a reading group of Algorithms of oppression by Safiya Noble. These questions of decolonisation of course extend to Al algorithms, surveillance technologies etc as well. Nurul and I have also been talking more about developing this further, and in terms of querying, for example, media theory or decolonising artificial intelligence. And I think I remember, Nazry, you were also involved in the conversation, about what does that mean for the digital humanities.

Nazry Bahrawi: One of the possibilities of the reading group that we were thinking about was to look at science fiction as a way into understanding the workings of science, and also to try to then expand the existing idea of science fiction. We haven't really got into this properly yet, but we were just talking about it, of reading science fiction from a non-Western context. And what that says about the production of knowledge in terms of the production of STS [Science, Technology \& Society] knowledge. As you can see from our background, none of us are really quite trained very technically. I come only from a university that is engineering-centric, very STEM-oriented, so I get a first-hand account of the kind of scepticism towards the humanities that exists, and Singapore is going the way of big data. Big data was something that we touched on.

Ada Sharif: We did have a series of reading group sessions in collaboration with Tanah. Through those sessions, we unpack together things like agrarian transformations in Southeast Asia, urbanisation and agro-ecology and a host of other associated topics with regard to ecology and whatnot. 
Jürgen Rudolph: I wanted to attend your Critical Karaoke session and after your presentation, I feel even worse for not having made it, unfortunately. How do you advertise your events? Do you have an email list or something like that because I would love to be on it and participate in future sessions?

Ada Sharif: We bootstrap a lot of our endeavours really. All the information that you need, you can just connect with us on Facebook. I guess that's the simple answer.

Nazry Bahrawi: We realise that this also means that people who do not use Facebook may not get to know of our events, then it actually closes off a certain group of people who may want to attend, but don't know how to or don't want to join Facebook. We are in the conversation about possibly extending our reach beyond Facebook. This is one of our challenges, I think. You've mentioned that we could maybe talk a bit about challenges. For me, it made me think about how to move on in the future in terms of outreach, but also in terms of an informal group and what our plans might be.

Whether we should somehow formalise a little bit more, or not at all. And this is something that we're still discussing and we don't have an answer to yet. But certainly I think that limiting ourselves to Facebook is an issue if we just limit our space to it.

Jürgen Rudolph: All the social media outlets come with their own problems, obviously.

Shawn Chua: We've had conversations about techno animism, for example, I think indigenous knowledge is definitely something that it's in the ether. There were a few programs that at least touched on notions of indigeneity.

Ada Sharif: All that is coming up to my mind is that one session we had with Tiantai Buddhism? We also had another session about Dalit Theology.

Shawn Chua: Information and data is not just flat, value neutral. Right. Some of this knowledge and data belongs to particular communities and it means certain kinds of things that then become radically and quite violently decontextualised and be regarded as transacted through a different panel.

Ada Sharif: If I may just add, we do have participants who do come regularly for sessions, who are part of another kind of informal reading group called the Decolonial Reading Group, here in Singapore. They really do go pretty in depth with decolonising knowledge and decoloniality. We do have Zoom sessions now and again as well. The whole community is just an overlapping and intersecting collective of people who are interested in many different things. Sometimes you might see each other in certain events but sometimes not in others. I think that's the beauty of it being open.

Shawn Chua: That's such a great point because it's important to understand that Bras Basah Open is not one entity. It's more than an entity. It's a mesh. It flourishes because of its promiscuity. Earlier I was talking about the dynamics of pairing. But this kind of extends that even further, whether it's through the kinds of collaborations with NGOs or different meeting groups or different communities. Much of our work is supported by the disenchantment of academics, who are more than happy to give their time and talk to us for free, for example. They're usually very happy to do that because they can then begin to take the work that they're doing and circulate that outside the academic spaces as well. But something that we've received quite a bit of feedback on, from the speakers, is to be transparent. We can't afford to pay people and speakers, unfortunately. And I think this becomes especially an issue when we're trying to engage with fellow peers and artists who may not necessarily have the stability of a full time job to come and share their knowledge. Actually sometimes we do ask for donations for events, we usually have a kind of recommended donation but it's pay-as-you-wish. Sometimes we try to give some of that money to speakers.

Nazry Bahrawi: Sometimes we also work with official bodies such as the Singapore Writers Festival, where we actually curate events. Then we can gain access to funds to pay people who work with us. We've done that with the Singapore Writers Festival. But, we've also done that with the Canadian High Commission recently when Nurul Huda hosted a talk with Kamal Al-Solaylee.

Stevphen Shukaitis: There's just something quite interesting about the way you talked about the dynamics of care in what you do. This strikes me that that's shared across people working in, let's say, independent literature or music or many things because there's lots of activities that, if just viewed on strictly a cost benefit analysis are just never going to survive. And it's something you do because you care about it, It's a continued existence, rather than an outcome or benefit.

Shawn Chua: Which is why I think sustainability and burnout become a big question. What is that maintenance labour, if you're talking about costs, who can afford to do this? Also, how can we continue to support people? I'm not sure if this is a question that we have fully resolved. It's not like we have a five-year plan, for example. But because of that we can also respond very tactically to things as they are arising very quickly. Farhan responds so quickly when a crisis emerges, he's actually the one who pitched the idea of developing a fundraiser for that. Or immediately trying to see opportunities to foster those kinds of collaborations. Coming back to the question of care and cost benefit analysis. Maybe it's not about thinking through a kind of scarcity of what is the cost of care or how much care you can give. And I guess it's important to take a step back and to think about how we think about the wider ecology as a kind of network of support that is happening, even outside the five of us and how these institutions try to support us also. Whether it's through financial support that comes through something like Singapore Writers Festival or some paid events. I think people who try to link us to different kinds of networks. I see those kinds of modalities to support kind of circulating.

Stevphen Shukaitis: It was just interesting thinking about the way, for instance, my university will divide people into academic staff and non-academic support staff, as if the 
work done by non-academic support staff isn't completely integral and necessary for ongoing knowledge and learning to even occur in the first place. That kind of separation between what is really academic work and what is everything else is kind of superfluous. Or at least a lot more blurred than it seems.

Nazry Bahrawi: We have been at the forefront of content production, but we've also just carried chairs and set up stuff. That line between what is academic and what isn't doesn't really fly with us.

Shawn Chua: Or rather we were beginning to find that these kinds of strict boundaries of what is academic or not is precisely what is suffocating the production of these kinds of knowledges as well. I think part of our work then is to repartition those kinds of sensibilities, to open up a different possibility so that people who are coming in can see that 'hey, actually, you know what, thinking about film as a kind of critical theoretical object'; not just as an object of study, but to think about how a film is producing theory. I think that that becomes a kind of invitation that we want to open up. How can we be a bit more playful also, and these are the kind of possibilities that a space like Bras Basah Open can do. Maybe people who are operating strictly within academia might be a little bit more constrained in what is legible as 'proper academia.'

\section{Additional references}

Alatas, S. F., \& Sinha, V. (2017). Sociological theory beyond the canon. Springer.

Chamberlain, J. A. (2018). Undoing work, rethinking community: A critique of the social function of work. Cornell University Press.

Diagne, S. B. (2018). Open to reason: Muslim philosophers in conversation with the Western tradition. Columbia University Press.

Gotman, K. (2017). Choreomania: Dance and disorder. Oxford University Press.

Harney, S., \& Moten, F. (2013). The undercommons. Fugitive planning \& black study. Minor Compositions.

Noble, S. U. (2018). Algorithms of oppression: How search engines reinforce racism. NYU Press.

Shukaitis, S. (2019). Combination acts: Notes on collective practice in the undercommons. Brooklyn: Autonomedia.

Smith, M., \& Mac, J. (2018). Revolting prostitutes: The fight for sex workers' rights. Verso Trade.

Copyright: @ 2021 Bras Basah Open: School of Theory \& Philosophy. This is an open-access article distributed under the terms of the Creative Commons Attribution License (CC BY). The use, distribution or reproduction in other forums is permitted, provided the original author(s) and the copyright owner(s) are credited and that the original publication in this journal is cited, in accordance with accepted academic practice. No use, distribution or reproduction is permitted which does not comply with these terms. 